\title{
Yvan Combeau, Edmond Maestri (sous la direction de), Histoire de la Réunion: de la colonie à la région
}

\section{Maria Clara Pellegrini}

\section{(2) OpenEdition}

12 Journals

\section{Edizione digitale}

URL: http://journals.openedition.org/studifrancesi/36837

DOI: 10.4000/studifrancesi.36837

ISSN: 2421-5856

\section{Editore}

Rosenberg \& Sellier

\section{Edizione cartacea}

Data di pubblicazione: 1 juillet 2005

Paginazione: 211

ISSN: 0039-2944

\section{Notizia bibliografica digitale}

Maria Clara Pellegrini, «Yvan Combeau, Edmond Maestri (sous la direction de), Histoire de la Réunion: de la colonie à la région», Studi Francesi [Online], 145 (XLIX | I) | 2005, online dal 30 novembre 2015, consultato il 18 avril 2021. URL: http://journals.openedition.org/studifrancesi/36837 ; DOI: https:// doi.org/10.4000/studifrancesi.36837

\section{Questo documento è stato generato automaticamente il 18 avril 2021.}

\section{(c) (1)}

Studi Francesi è distribuita con Licenza Creative Commons Attribuzione - Non commerciale - Non opere derivate 4.0 Internazionale. 


\title{
Yvan Combeau, Edmond Maestri (sous la direction de), Histoire de la Réunion : de la colonie à la région
}

\author{
Maria Clara Pellegrini
}

\section{NOTIZIA}

YVAN COMBEAU, EDMOND MAESTRI (sous la direction de), Histoire de la Réunion : de la colonie à la région, Paris, Nathan, 2002, pp. 160.

1 Occupata dai Francesi nel 1642 come settler colony (colonia di popolamento), l'isola deserta della Réunion ha ignorato, quindi negato fino alla seconda metà del Novecento parte della propria storia coloniale rivendicando la priorità e la superiorità della tradizione culturale dei primi colonizzatori francesi. Il dovere della memoria si impone oggi, a più di mezzo secolo dalla dipartimentalizzazione dell'isola, perché la Réunion possa finalmente reclamare la propria emancipazione dalla madrepatria. Citiamo in proposito Paul Vergès, Presidente del Consiglio Regionale: "Il s'agit pour le jeune Réunionnais issu d'ancêtres de toutes origines et de toutes cultures de se situer aujourd'hui en tant que tel, de définir sa vision du monde et l'idée de la place qu'il doit y occuper. Il s'agit de s'assumer en assumant tout un passé de négation des droits humains pour le plus grand nombre. Il y a donc l'impérieuse nécessité d'un devoir de la mémoire" (p. 2). Il testo, curato dal CRESOI (Centre de Recherches sur les Sociétés de l'Océan Indien), partendo dal confronto con la storia francese, si pone l'obiettivo di restituire la storia generale della Réunion, dalla colonizzazione fino allo statuto di regione del 1982. Il volume si divide in quattro sezioni: dalla colonizzazione all'abolizione della schiavitù (1848), passando per l'amministrazione della Compagnia delle Indie, e la Rivoluzione francese; dal 1848 alla Prima Guerra Mondiale; dal 1919 al 1939; dal Secondo conflitto al 1982. Corredato da una dettagliata cronologia aggiornata 
al 2002, il testo unisce alla sintesi rigorosa dei temi trattati un'interessante lettura critica degli eventi. 